\title{
Bioética, saúde e meio ambiente: Parâmetros curriculares nacionais e temas transversais
}

\section{Bioethics, health and the environment: national curricular parameters and transverse topics.}

\author{
Leonardo Eustáquio Sant'Anna da Silva \\ Cátedra Unesco de Bioética (UnB), Brasília, Distrito Federal, Brasil \\ leoeustaquio@gmail.com
}

\author{
José Roque Junges \\ Cátedra Unesco de Bioética (UnB), Brasília, Distrito Federal, Brasil \\ jrjunges@unisinos.br
}

Resumo: A bioética é um campo de discussão transdisciplinar que possibilita a integração de saberes. Por meio de suas temáticas podemos envolver os temas saúde e meio ambiente. Com esta integração a bioética permite uma avançada reflexão que pode ser levada para escolas de ensino fundamental e médio gerando importantes instrumentos para os sujeitos envolvidos. Mas deve-se alertar que o ensino dogmático não é capaz de abarcar estas discussões, pois a bioética está intrinsicamente ligada à reflexão autônoma. Este artigo propõe-se a articular questões bioéticas para alunos cursando o ensino fundamental e médio propondo como plano de fundo a proposta interdisciplinar dos Parâmetros Curriculares Nacionais.

Palavras-chave: Bioética. Saúde. Meio ambiente. Ensino fundamental e médio.

\begin{abstract}
Bioethics is a transdisciplinary field of discussion that enables integration of knowledge. Through its themes, the topics of health and the environment can be involved. With this integration, bioethics enables advanced reflection that can be taken to elementary and high schools, thereby generating important instruments for the subjects involved. However, it needs to be noted that dogmatic teaching is incapable of embracing these discussions, since bioethics is intrinsically linked to autonomous reflection. This paper had the aim of articulating bioethical questions for students in elementary and high schools, with the interdisciplinary proposal for national curricular parameters as its basis.
\end{abstract}


Key words: Bioethics. Health Environment. Elementary and high school.

A necessidade de refletir sobre bioética na vida cotidiana é um pressuposto abarcado pelo seu conceito original. Potter, primeiro autor a sistematizar este conceito, ao escrever seu livro Bioética - uma ponte para o futuro, em 1971, sustentou que a bioética deveria ser uma possibilidade de discussão e reflexão sobre diferentes dilemas éticos da vida. Neste sentido ela parte da visão científica das relações entre o homem e a natureza, diferenciando-se de uma relação puramente instintiva para com ela. Potter afirma ainda que a bioética não deve ser uma disciplina, mas um campo interdisciplinar presente no conceito de ponte para o futuro (1).

A bioética, enquanto ética aplicada à vida cotidiana e como uma "ética prática - que se ocupa do agir correto ou do bem-fazer" (2), precisa ser discutida nas escolas de ensino fundamental e médio, possibilitando a formação reflexiva dos alunos, fornecendolhes ferramentas que possibilitem ações autônomas, uma vez que terão a possibilidade de pensar os dilemas éticos que surgirão em suas vidas profissionais e pessoais de forma independente.

A convergência da discussão da bioética, da saúde coletiva e do meio ambiente não é meramente técnica, mas uma necessidade urgente para que os temas sejam abordados transdisciplinarmente e relacionados com a prática dos indivíduos. As discussões precisam integrar os conhecimentos produzidos de forma contextualizada para que a bioética permita a reflexão sobre os paradigmas da saúde e do meio ambiente (3). Assim a tríade saúde, meio ambiente e bioética podem se tornar, por sua importância formativa, uma pauta constante da realidade das escolas.

Para Pires e Garrafa (4) deve-se pensar um ensino que seja capaz de levar, desde cedo, a discussão ética para a formação de crianças e adolescentes, libertando-os de determinismos impostos pela sociedade. Nesta perspectiva, o ensino deve se preocupar com as mazelas do planeta e com as questões socioculturais que envolvem o contexto de vida dos próprios indivíduos. Afinal, "esta reorientação pode contribuir para a busca da humanização e pacificação das relações humanas, estimulando a reconciliação do homem com a natureza" (4).

Em Paulo Freire, lemos que é fundamental que o educador não abra mão de uma pedagogia fundamentada no exercício da autonomia, pautada na "ética e no respeito à dignidade e à própria autonomia do educando" (5), reforçando ainda que: "o respeito à autonomia e à dignidade de cada um é um imperativo ético e não um favor que podemos 
ou não conceder uns aos outros" (5).

É nesse contexto que os Parâmetros Curriculares Nacionais (PCNs) podem contribuir dando uma sustentabilidade legal para entrada da bioética nos currículos escolares de escolas de ensino fundamental e médio (6). O PCN volume 10.4 - Temas Transversais - Saúde (7), por exemplo, orienta que a aprendizagem deve ser efetivamente voltada para uma educação transformadora de atitudes e hábitos de vida, mas orientado para a reflexão constante sobre o que é saúde, como deve ser a formação para a cidadania, quais são os serviços de saúde que um cidadão tem direito, dentre outras reflexões fundamentais para a construção de um ser humano de direitos.

O PCN volume 10.3 - Temas Transversais - Meio Ambiente, também é claro ao afirmar que: "o debate na escola pode incluir a dimensão política e a perspectiva da busca de soluções para situações como a sobrevivência de pescadores na época da desova dos peixes, a falta de saneamento básico adequado ou as enchentes que tantos danos trazem à população" (8). sendo assim, o debate sobre o meio ambiente deve estar contextualizado na realidade vivida pelos alunos e referenciado na sua dimensão física e pautada nas questões práticas que o rodeiam.

Por fim, elenca-se o PCN volume 10.2 - Temas Transversais - Ética, Pluralidade cultural e orientação sexual, como sendo um marco referencial para bioética, pois referenda todas as questões bioéticas dando a elas uma dimensão cultural imprescindível em sua apresentação: "a escola deve ser local de aprendizagem de que as regras do espaço público permitem a coexistência, em igualdade, dos diferentes [...] baseada na tolerância, no respeito aos direitos humanos e na noção de cidadania compartilhada por todos os brasileiros" (9).

\section{A reflexão bioética em escolas}

Para Neri (10) o comportamento moral é dinamizado e interiorizado por meio da aprendizagem. Ele resulta de um processo educativo que deve evoluir constantemente no sentido integral do desenvolvimento global do indivíduo, completando a dimensão moral com a cognitiva. A escola então se torna uma ferramenta importante para a formação de indivíduos competentes no uso de uma moral bem desenvolvida, tendo presente a teoria do desenvolvimento moral de Kohkberg (10), que divide a formação moral em três níveis de desenvolvimento: pré-convencional, convencional e pós-convencional. Onde o nível mais simples seria aquele em que as crianças concebem a moralidade somente em termos de obediência à autoridade para evitar a possíveis punições e o último estágio, 
e o mais maduro, seria aquele onde as pessoas são orientadas pelo comportamento moral autônomo, pois eles mesmos conseguem perceber autonomamente, baseados na racionalidade, o que deve ou não deve ser feito (10).

Zagury (11) afirma, em suas pesquisas, que os jovens têm plena consciência da importância da escola para sua formação, ainda que não gostem de estudar. Reforça que bons ou maus alunos não definem exatamente se serão bons ou maus cidadãos, exemplificando que Einstein era um péssimo aluno e foi genial fora da escola. Por isso a escola não deve se preocupar somente com conteúdos ou formar pessoas para a continuidade de estudos universitários, mas deve preparar para a convivência em sociedade.

Os PCNs (6) fundamentam o modo de se apresentar uma série de conteúdos e disciplinas nas escolas do país. Nele tomam destaques os temas transversais, não como uma nova disciplina, mas como um formato de atuação reflexiva transdisciplinar que leva para o debate nas escolas os conteúdos da vida cotidiana (6). Dentro dos temas transversais elencados pelos PCNs, destaca-se a saúde, o meio ambiente e a ética, os temas que são balizadores de uma educação crítica e cidadã nas escolas públicas e particulares.

Os conteúdos transversais devem ser apresentados aos alunos pela integração das disciplinas com suas práticas, repensando os aspectos culturais da sua vida cotidiana. Para essa apresentação se deve levar em consideração o pluralismo moral existente na sociedade, não desenvolvendo os temas como respostas prontas aos desafios morais existentes (6). Neste sentido, a apresentação dada pelos PCNs é confluente com o pensamento da bioética apresentada por Siqueira (12) ao compreender que os modelos doutrinários de educação não são adequados para a discussão desses temas. Modelos doutrinários possuem ênfase em dogmas indiscutíveis, baseados em verdades absolutas e provenientes de uma autoridade superior, não permitindo a discussão e deliberação do tema e mantendo uma relação de subserviência com um agente superior, incapaz de gerar autonomia moral nos estudantes.

A compreensão de que os temas transversais devem sustentar-se na possibilidade de gerar autonomia de reflexão entre seus participantes, reforça que "a escola deve ser um lugar onde os valores morais são pensados, refletidos e não meramente impostos ou frutos do hábito" (6). Por isso o caminho adequado é oferecer modelos de reflexão ética que instrumentalizem os estudantes a encontrarem as próprias soluções para os dilemas éticos que encontrem ao longo de sua vida. A apresentação desses problemas deve ser gradual e compatível com sua compreensão para que possam discutir e encontrar soluções contextualizadas com as suas compreensões morais e possibilidades práticas. 
Apresentar dilemas distantes de sua vida cotidiana e aparentemente desconectados de suas práticas futuras não contribui para uma educação em bioética, mantendo uma educação meramente tradicional e acumuladora de conhecimento (12).

Kant apresenta a autonomia como uma atividade da vontade, uma ação que é gerada pelo próprio indivíduo e, nesse sentido, a lei moral a ser seguida não vem de fora para dentro (10). A autonomia kantiana poderia ser confundida como uma ação que desrespeita o outro, mas é justamente o contrário, uma vez que o imperativo categórico para Kant é: "Age de tal modo que a máxima de tua vontade possa sempre valer simultaneamente como um princípio para uma legislação geral” (10). Desta forma, a autonomia permite que as pessoas tomem suas decisões, tendo como referência os outros, percebendo que sua vontade deve ter a possibilidade de valer para as demais (10). Desta forma, as escolas precisam trabalhar a autonomia intelectual de seus alunos, para que eles possam formular seu próprio pensamento e atingir o último estágio do desenvolvimento moral de Kohkberg, no qual decidam com autonomia e saibam se colocar no lugar do outro.

Pensando a bioética como "a procura de um comportamento responsável de parte daquelas pessoas que devem decidir os tipos de tratamento e de pesquisa com relação à humanidade" que "fundamenta-se por meio de uma ação multi-intertransdisciplinar que inclua, além das ciências médicas e biológicas, também a filosofia, o direito, a teologia, a antropologia, a ciência política, a comunicação, a sociologia, a economia", "podemos afirmar, portanto, que toda ética é, antes e fundamentalmente, uma bioética" (13). Partindo desse referencial teórico, pode-se reforçar a necessidade da discussão bioética em todos os níveis de ensino.

A bioética de intervenção divide os problemas de nossa sociedade em situações emergentes e situações persistentes. Entendem-se como bioética de situações emergentes aquelas que lidam, nas últimas décadas, com questões éticas do desenvolvimento biotecnológico (14), como exemplo cita-se as questões de engenharia genética, reprodução assistida, células-tronco, dentre outras. Bioética de situações persistentes são aquelas vinculadas às condições das sociedades humanas desde a antiguidade (14), como exemplos as questões raciais, questões sanitárias básicas, alocação de recursos públicos em saúde, dentre outras. Assim, a bioética é um campo gerador de grandes discussões reflexivas que abarcam a saúde individual e coletiva, pública e privada e o meio ambiente. Esses dois tipos de problemas bioéticos precisam ser abordados pelos currículos transversais das escolas.

As pesquisas apresentadas por Pires e Garrafa (4) demonstram o quanto 
os professores de escolas públicas e particulares do Distrito Federal clamam pela possibilidade da formação mais ampla dos alunos, com a inserção da bioética, "uma vez que as desigualdades sociais fragilizam as noções de cidadania, dificultando ou mesmo impedindo a tomada de decisões conscientes e autônomas" (4).

Suscitar discussões referentes às situações emergentes e persistentes em sala de aula, possibilitando a discussão por meio de referenciais éticos não dogmáticos, permite que os alunos possam encontrar seus próprios caminhos na procura de soluções de dilemas vivenciados ou que ainda o serão no futuro, dando a eles a possibilidade de se instrumentalizarem com os pressupostos teóricos necessários para sua atuação prática, independente da sua área profissional.

\section{Meio ambiente, bioética e educação para responsabilidade}

Segundo Garrafa, a "conotação original (da palavra ética) se relacionava com uma questão de ética global, ou seja, com a preocupação ética de preservação futura do planeta" (13). Neste sentido pode-se entender a bioética como uma "ética planetária, preocupada com a responsabilidade, a médio e longo prazo, pelos efeitos daninhos que podem resultar dos atos humanos sobre a vida humana individual, a vida social e cultural, a biosfera e a ecosfera como um todo" (1).

Para Morim, a educação deve se converter em uma ética planetária e não em um pensamento unicamente comunitário, abrindo-se "à esperança na completude da humanidade, como consciência e cidadania planetária" (15). A ética está baseada na consciência individual, mas seu âmbito está "para além da individualidade e da comunidade" (15). Ela não pode reduzir-se ao local, mas abranger o planetário, em uma cidadania mais ampla e complexa, compreendida como uma "pátria terrestre" (15).

Gadotti ressalta que hoje temos uma concepção consumista de cidadania, para a qual cidadão como indivíduo deve consumir, para fazer parte da polis, como se o comprar fosse uma característica imprescindível para o portador de direitos e, sem ela, não seria possível resguardar ao sujeito seu espaço em sociedade (16). Para Gadotti, devemos educar para a cidadania planetária (16), reafirmando o termo de Morim, de uma cidadania que é plena, que não se limita a direitos individuais, mas que se concretiza na mobilização de uma sociedade que constrói direitos para todos e que são garantidos pelo Estado. Um cidadão planetário é aquele que cumpre com seus deveres, leis, responsabilidades (como impostos), não se exime da vida política escolhendo conscientemente seus representantes por meio do voto. Gadotti reforça ainda que, para chegarmos à cidadania planetária, não 
somente as escolas devem trabalhar para isso, mas toda a sociedade (16).

Ao compreendermos a bioética como uma ética planetária é impossível não implicar as reflexões fundamentais sobre a continuidade da vida no planeta, não uma vida qualquer, mas uma vida de qualidade e de possibilidades para seres humanos e demais seres vivos do planeta. Para discussão destas categorias, faz-se necessário refletirmos sobre conceitos enunciados por Hans Jonas em seus conceitos de ética da responsabilidade (17).

O grande choque causado pelas bombas atômicas de Hiroshima e Nagasaki foi um marco para a mudança de pensamento das pessoas com relação ao domínio do ser humano sobre a natureza. Este é o fundamento de Jonas para despertar as pessoas para a possibilidade eminente da destruição do planeta pelo ser humano. Se não for a destruição brusca, a possibilidade de uma destruição gradual, que seria consequência das decisões dos seres humanos, que tomam para si o poder sobre o planeta, podendo decidir sobre a sua continuidade (17).

Hans Jonas aborda três aspectos que devem ser analisados: a ética da responsabilidade individual, ética da responsabilidade pública e ética da responsabilidade planetária. As três categorias devem estar incluídas na ação educativa e nas possibilidades de discussão para reflexão de estudantes.

A ética da responsabilidade individual "se refere ao papel e compromissos que cada um deve assumir a si mesmo e aos seus semelhantes, seja em ações privadas ou públicas, singulares ou coletivas" (15), assim os educadores devem suscitar a discussão com seus alunos no sentido de levar a reflexão de quais são as responsabilidades práticas de ações individuais que afetam a coletividade. Nesse sentido, as discussões temáticas sobre o consumo de água ou escolhas sustentáveis com menor impacto ambiental estão em consonância com a responsabilidade individual sobre o meio ambiente.

A ética da responsabilidade pública de Jonas, “diz respeito ao papel e aos deveres dos Estados frente não só a temas universais como a cidadania e os direitos humanos, mas também com relação ao cumprimento das cartas constitucionais, principalmente nos capítulos referentes diretamente à saúde e à vida das pessoas" (13). Assim, a reflexão das ações públicas, seja na ação do agente público ou dos indivíduos enquanto cidadãos, deve ser elencada como tema de discussão em sala de aula. Esta atividade possibilita a reflexão na formação do cidadão e no cumprimento dos deveres dos futuros agentes públicos.

Por fim, a ética da responsabilidade planetária, "que significa o compromisso de cada um de nós, como cidadãos do mundo, de cada país e do próprio conjunto de todas as nações, frente ao desafio da preservação do planeta, em respeito àqueles que 
virão depois de nós" (13), aponta para a necessidade da investigação bioética para que os alunos possam identificar sua própria responsabilidade com o meio ambiente, com sua saúde com os demais integrantes do planeta.

Jonas propõe um novo imperativo: Age de tal maneira que os efeitos de tua ação sejam compatíveis com a permanência de uma vida humana autêntica (18). Este princípio também é gerador de reflexões bioéticas que ultrapassam a ação de uma disciplina, requerendo assim a abordagem transdisciplinar que tenha o meio ambiente como fundo, mas que permita uma investigação pessoal dos alunos sobre suas ações, gerando conhecimentos que venham pautar sua vida prática, seja formadora de atitudes futuras frente a outros problemas práticos que irão se apresentar.

\section{Saúde como uma possibilidade de reação}

A escola deve ser um local de promoção de saúde. Para isso, "em primeiro lugar é preciso uma redescoberta daquilo que se chama saúde psicológica e do paradigma da psicologia positiva. Sair do paradigma da doença para o da saúde” (19). A construção da saúde passa por esta quebra de paradigma, necessitando de uma discussão aprofundada sobre os conceitos e as ações promotoras de saúde, indo além da apresentação de puros conceitos, implicando a prática dos alunos e suas respectivas famílias e promovendo a reflexão de todos os sujeitos envolvidos.

É preciso compreender a saúde com uma concepção ampliada do processo saúde-doença, que não identifica saúde com um simples estar bem ou como a ausência de doenças (20). É fundamental que se compreenda a saúde a partir de uma visão integral do ser humano, em toda sua completude, como um ser biológico, social, psicológico, religioso, etc. Saúde não é um estado estável e homogêneo, porque abarca em sua compreensão as questões culturais que afetam a saúde das pessoas e das comunidades.

Segundo os PCNs, um dos objetivos da abordagem transdisciplinar nas discussões de saúde é "compreender que a condição de saúde é produzida nas relações com o meio físico, econômico e sociocultural, identificando fatores de risco à saúde pessoal e coletiva presentes no meio em que vivem" (6). Para tanto, a bioética deve se envolver nessa discussão, promovendo o debate sobre as situações emergentes e persistentes e possibilitando a ação reflexiva entre os sujeitos envolvidos.

Para a discussão de saúde são importantes os aspectos que dizem respeito a sua dimensão estrutural, compreendendo que os processos de exclusão social, em suas dimensões social e particular, afetam a capacidade de reação e enfrentamento dos 
indivíduos e grupos sociais diante da doença (21). Daí ser é indispensável estabelecer um conceito de saúde tomada como capacidade de reação diante da doença, despertando para a mobilidade e para o não ser passivo (21).

Rocha, Ferriani e Souza (22) entendem a escola como um espaço de relações de diferentes contextos sociais, econômicos, culturais, políticos, dentre outros, o que a confere o privilégio de ser um grande espaço de construção de cidadania. Além disso, a escola ainda conta com outra característica muito privilegiada: o envolvimento de diversos atores sociais - alunos, família, professores, comunidade e profissionais de saúde.

Para as autoras, a escola deve ser um local de promoção da saúde, levando em consideração cinco grandes objetivos: a) desenvolver ações de promoção de saúde através de práticas interdisciplinares e intersetoriais; b) desenvolver compreensão, habilidades, atitudes visando à saúde do adolescente; c) apoiar, implementar e ampliar grupos de convivência, discussão, capacitação em torno de experiências educativas extracurriculares de adolescentes em escolas; d) estimular a participação de adolescentes nos processos sociais e da escola, no sentido de se tornarem corresponsáveis por sua própria saúde; e) promover a conscientização dos adolescentes e contribuir para a formação de seres humanos autônomos, com capacidade de realizar escolhas e tomar decisões de acordo com seus valores, expectativas, necessidades, prioridades e crenças pessoais; voltados para a realidade socioambiental de um modo geral, comprometidos com a vida, com o bem-estar de cada sociedade local e global e contribuindo para a construção de um mundo socialmente justo e ecologicamente equilibrado (22).

Com isso, pode-se perceber a importância do trabalho interdisciplinar e coletivo entre diferentes equipes, a preocupação com o contexto social, político e econômico, a relevância da autonomia e como os PCNs podem contribuir como elemento fomentador para o apoio curricular. Esta visão pode ser amplamente discutida na escola: como os alunos podem reagir diante dos paradigmas de doenças em que estão diariamente envolvidos?

Um bom exemplo desse conceito seria sua aplicação nas discussões sobre o Bullying, um problema vivenciado universalmente em escolas. O bullying é conceituado como uma ação de violência e vitimização representada em diferentes tipos de envolvimento em situações durante a infância e adolescência, "diz respeito a uma forma de afirmação de poder interpessoal através da agressão" (23). Segundo Lopes, a aceitação pelos companheiros é fundamental para o desenvolvimento da saúde de crianças e adolescentes, aprimorando suas habilidades sociais e fortalecendo a capacidade de reação diante de situações de tensão (23). Sendo assim, deve-se tratar a reflexão sobre o conceito 
de saúde como uma possibilidade de se movimentar, de sair da estática condição de vitimização do bullying, gerando novas possibilidades para criar uma situação mais saudável para os sujeitos envolvidos.

Outra questão fundamentalmente bioética é a discussão quanto à medicalização nas escolas hoje. A procura por culpados é uma constante, os pais dos alunos não desejam assumir a responsabilidade, os alunos não assumem os resultados de seus atos, os professores e a escola também passam a bola e as indústrias de medicamentos enxergam nesse sistema um grande nicho de mercado, justificando a improdutividade dos alunos com supostas doenças, gerando um crescente ganho financeiro para essas indústrias. A justificativa é que os alunos não são irresponsáveis, os pais não são relapsos, os professores não são omissos, as escolas não são fracas, mas o grande problema é a doença, uma síndrome que somente o remédio poderá salvar. Lepargneur alerta para um perigo ainda maior, o doping pelo uso de ritalina, uma anfetamina, usada por jovens saudáveis na procura de um melhor desempenho acadêmico (24).

\section{Considerações finais}

A bioética possibilita a discussão em escolas de ensino fundamental e médio de temas extremamente relevantes para os jovens que vivenciam uma série de conflitos e precisam de um suporte teórico para sua tomada de decisões. Adolescentes passam por dilemas éticos diariamente e necessitam de uma discussão prévia para que tenham suporte para suas escolhas verdadeiramente autônomas no sentido kantiano de pensar por si mesmo, mas para pensar é necessário ter conhecimento.

Os PCNs permitem, didaticamente, a entrada da fundamentação teórica da bioética nas discussões escolares, fazendo com que temas como saúde e meio ambiente integrem as atividades reflexivas de uma maneira transdisciplinar, para que elas não se transformem em uma nova disciplina ou campo do saber, mas sejam transversais nas discussões e nas práticas vivenciadas em sala de aula ou fora dela, tendo presente os diferentes espaços e agentes atuantes nesse meio.

Essa abordagem não pode se pautar em modelos doutrinários, mas deve promover a discussão e incentivar a procura por soluções autônomas para que os sujeitos possam encontrar suas próprias saídas e soluções para os problemas que enfrentam. Desse modo, aumentariam os recursos teóricos e argumentativos que esses alunos teriam nas bagagens culturais de suas carreiras, capacitando-os para enfrentar futuros dilemas éticos. As discussões permitirão uma compreensão da saúde como capacidade 
de reação, livrando-se dos discursos medicamentosos que tomam conta do mercado, para que a cidadania sanitária não seja sinônimo do consumismo de ofertas de mercado das indústrias biotecnológicas e que o meio ambiente seja preservado com responsabilidade para as futuras gerações e para a reprodução da vida de todos seres vivos.

\section{Referências}

1. Schramm FR. A bioética, seu desenvolvimento e importância para as ciências da vida e da saúde. Revista Brasileira de Cancerologia. 2002; 48(4):609-615.

2. Costa SIF, Garrafa V, Oselka GW, organizadores. Iniciação à bioética. Brasília: Conselho Federal de Medicina; 1998.

3. Junges JR, Zoboli ELCP. Bioética e Saúde Coletiva: convergências epistemológicas. Cienc. saúde coletiva. 2012; 17(4):1049-1060.

4. Pires JR, Garrafa V. Educação: nova fronteira da bioética. Ciênc. saúde coletiva. 2011; 16 Supl.1: 735-45.

5. Freire P. Pedagogia da autonomia: saberes necessários à prática educativa. São Paulo: Paz e Terra; 1996.

6. Brasil. Ministério da educação e do desporto. Secretaria de Educação Fundamental. Parâmetros curriculares nacionais: apresentação dos temas transversais, ética. Brasília: MEC/SEF; 1997.

7. Brasil. Ministério da Educação e do Desporto. Secretaria de Educação Fundamental. Parâmetros curriculares nacionais: Temas Transversais - Saúde. Brasília: MEC/SEF; 1997.

8. Brasil. Ministério da Educação e do Desporto. Secretaria de Educação Fundamental. Parâmetros curriculares nacionais: Temas Transversais - Meio ambiente. Brasília: MEC/ SEF; 1997.

9. Brasil. Ministério da Educação e do Desporto. Secretaria de Educação Fundamental. Parâmetros curriculares nacionais: Temas Transversais - Ética, pluralidade cultural e orientação sexual. Brasília: MEC/SEF; 1997.

10. Neri D. Filosofia Moral - Manual introdutivo. São Paulo: Edições Loyola; 2004.

11. Zagury T. O adolescente por ele mesmo. 9 ed. São Paulo: Record; 2006.

12. Siqueira JE. Verbetes: Educación en bioética. In: Tealdi JC, organizador. Dicionario Latino-Americano de Bioética. Buenos Aires, 2006.

13. Garrafa V. Introdução à Bioética. Revista do Hospital Universitário UFMA. 2005; 6(2):9-13.

14. Cruz MR, Trindade ES. Bioética de Intervenção - uma proposta epistemológica e uma necessidade para sociedades com grupos sociais vulneráveis. Revista Brasileira de Bioética. 2006; 2(4):483-500.

15. Morin E. Os sete saberes necessários à educação do futuro. 2 ed. São Paulo/Brasília: 
Cortez/Unesco; 2000.

16. Gadotti M. Cidadania planetária: Pontos para a reflexão. Conferência Continental das Américas para a Carta da Terra; 1998 Nov. 30 - Dez. 3; Cuiabá, Mato Grosso.

17. Siqueira JE. Ética e Tecnociência: Uma abordagem segundo o princípio da responsabilidade de Hans Jonas. Londrina: EdUEL, 1998.

18. Jonas H. O principio vida: fundamentos para uma biologia filosófica. Petrópolis: Vozes; 2004.

19. Guzzo RSL. Saúde psicológica, sucesso escolar e eficácia na escola: desafios do novo milênio para a psicologia escolar. In: Del Prette ZAP, organizador. Psicologia escolar e educacional: saúde qualidade de vida. Campinas: Alínea, 2003.

20. Almeida FN, Juca V. Saúde como ausência de doença: crítica à teoria funcionalista de Christopher Boorse. Ciênc. saúde coletiva. 2002; 7(4):879-89.

21. Munoz SAI, Bertolozzi MR. Pode o conceito de vulnerabilidade apoiar a construção do conhecimento em Saúde Coletiva? Ciênc. saúde coletiva. 2007; 12(2): 319-24.

22. Rocha CRM, Ferriani MGC, Souza MSS. O acompanhamento do adolescente na escola. In: Ramos FRS, organizador. Adolescer: compreender, atuar, acolher. Brasília: ABEn; 2001.

23. Lopes NAA. Bullying: comportamento agressivo entre estudantes. J. Pediatr. 2005; 81 Supl.5:164-172.

24. Lepargneur H. Promoção da humanidade futura: enhancement. Revista Bioétikos. 2010; 4(3):310-314.

\section{Recebido: 11/07/2011 Aprovado: 27/11/2011}

